\title{
Association between Copper-Zinc Ratio in Hair and Neutrophil-Lymphocyte Ratio within the Context of a Normal White Blood Cell Count among Overweight or Obese Korean Individuals: A Pilot Study
}

\author{
Sun Young Jeong, Hyo Young Shim, Yong Jae Lee, Byoungjin Park* \\ Department of Family Medicine, Yonsei University College of Medicine, Seoul, Korea
}

\begin{abstract}
Background: Obesity is considered a state of enhanced oxidative stress as well as chronic and low-grade inflammation. The copper-zinc ratio in obese individuals has been reported to reflect systemic oxidative stress and inflammatory status. We investigated whether the neutrophil-lymphocyte ratio is related to the copper-zinc ratio in hair, within the context of a normal white blood cell count among overweight or obese Korean individuals.

Methods: We included 56 participants aged older than 20 years who voluntarily sought weight reduction treatment and met the inclusion criterion of body mass index of $23 \mathrm{~kg} / \mathrm{m}^{2}$ or greater. Intra-abdominal visceral adipose tissue was measured by computed tomography imaging, while the copper and zinc levels were measured by hair mineral analysis. Using multiple linear regression analysis, we examined the associations between the neutrophil-lymphocyte ratio and the copper-zinc ratio.

Results: The mean age, body mass index, and visceral adipose tissue were $46.0 \pm 10.5$ years, $29.0 \pm 4.1 \mathrm{~kg} / \mathrm{cm}^{2}$, and $142.9 \pm 68.8 \mathrm{~cm}^{2}$, respectively. Pearson's correlation analysis revealed the association of the neutrophil-lymphocyte ratio with copper level $(\mathrm{r}=0.475, \mathrm{P}<0.001)$ and copper-zinc ratio $(\mathrm{r}=0.494, \mathrm{P}<0.001)$. After adjusting for confounding variables, we found the neutrophil-lymphocyte ratio was significantly associated with the level of copper and the copper-zinc ratio in hair (regression coefficient: $0.055 \pm 0.015 ; \mathrm{P}<0.001$ and regression coefficient: $0.761 \pm 0.185$; $\mathrm{P}<0.001$, respectively).

Conclusion: A higher copper-zinc ratio in hair is positively and independently associated with the neutrophil-lymphocyte ratio. Thus, a high hair copper-zinc ratio could be a useful parameter for oxidative burden of individuals predisposed to obesity-related comorbidity.
\end{abstract}

Keywords: Copper; Zinc; Hair Analysis; Neutrophil-Lymphocyte Ratio; Obesity; Oxidative Stress

Received: February 22, 2020, Revised: April 16, 2020, Accepted: April 25, 2020

${ }^{*}$ Corresponding Author: Byoungjin Park https://orcid.org/0000-0003-1733-5301

Tel: +82-31-5189-9160, Fax: +82-31-5189-8809, E-mail: bjpark96@yuhs.ac 


\section{INTRODUCTION}

Obesity is considered to be a state of enhanced oxidative stress as well as chronic and low-grade inflammation. ${ }^{1)}$ The excessive accumulation of fat in adipose tissue recruits macrophages and leads to the increased production of proinflammatory cytokines and chemokines, such as interleukin 6 and tumor necrosis factor- $\alpha$. In particular, visceral obesity is known to play a crucial role in the development of metabolic syndrome. ${ }^{2,3)}$ Thus, it is clinically important to evaluate the preclinical oxidative burden in obese patients.

White blood cell (WBC) count is one of the useful inflammatory biomarkers in clinical practice. A higher WBC count, even within a normal range, has been associated with atherosclerotic cardiovascular disease events and is also considered a marker of infection. ${ }^{4)} \mathrm{WBC}$ are composed of five different types of immune cells, and each subtype of WBCs exerts its own effects in different ways. Neutrophils and monocytes produce reactive oxygen species (ROS) and nitric oxide species (NOS), being chemically reactive molecules. ${ }^{5}$ Unless ROS and NOS are properly neutralized by the antioxidant defense system or molecules, they can cause damage to cellular structures and possibly DNA. More recently, the neutrophil-lymphocyte ratio (NLR) has been reported to predict cardiovascular risk. ${ }^{6,7)}$ In this regard, NLR within the context of a normal WBC count has been proposed as a useful indicator to assess the oxidative stress status. ${ }^{\text {g) }}$

Elevated copper is known to be associated with oxidative stress, inflammation, and reduced immune function. ${ }^{9-11)}$ in contrast, zinc, an antagonist mineral for copper, has antioxidant and anti-inflammatory properties and is essential for maintaining the immune system. Thus, the ratio of copper to zinc has been reported to reflect systemic oxidative stress. ${ }^{12)}$ Some previous studies have shown that chronic inflammatory diseases are associated with increased copper-zinc ratio. ${ }^{13,14)}$ If the oxidative stress increases as the ratio of copper to zinc increases or vice versa, we would expect positive associations between the copperzinc ratio and NLR with normal WBC count; thus, the copper-zinc ratio could be an additional surrogate marker for oxidative burden.

Hair mineral analysis is a noninvasive and useful test for assessing long-term mineral imbalance. Profiling the imbalance in hair minerals, such as an impaired ratio of mutually interactive minerals, might be a useful diagnostic tool for early-stage diagnosis in many diseases. ${ }^{15}$ ) Thus, we investigated whether NLR is related to the copper-zinc ratio in hair within the context of a normal WBC count among overweight or obese Korean adults.

\section{METHODS}

\section{Study Population}

We retrospectively reviewed the medical records of 68 sequential adults who voluntarily sought weight reduction treatment at the Department of Family Medicine, Yongin Severance Hospital, Yongin-si, Republic of Korea, between April, 2011 and May, 2013. We recruited overweight or obese Korean adults who met the inclusion criteria of a body mass index (BMI) of $23 \mathrm{~kg} / \mathrm{m}^{2}$ or more (the threshold value for generalized overweightness or obesity in Asia) and who underwent both hair mineral analysis and abdominal fat computed tomography (CT) imaging. Subjects meeting any the following criteria were excluded following a whole blood count analysis to rule out acute inflammatory disorders: WBC count of $<4.0$ or $>10.0\left(\times 10^{3}\right.$ cell $\left./ \mu \mathrm{L}\right)$. Ultimately, 56 participants ( 11 men and 45 women) were included in final analysis.

Participants were asked about their medical history, and height and body weight were measured to the nearest $0.1 \mathrm{~cm}$ and $0.1 \mathrm{~kg}$ while the participant wore light indoor clothing and no shoes. BMI was calculated as the ratio of weight $(\mathrm{kg})$ to the square of height $\left(\mathrm{m}^{2}\right)$. Following an 8-hour overnight fast, blood samples were taken from an antecubital vein. WBC counts were quantified by an automated blood cell counter (ADVIA 120; Siemens Healthineers, Erlangen, Germany) within 1 hour of blood sampling. Fasting plasma glucose, total cholesterol, triglycerides, and high-density lipoprotein (HDL) cholesterol were measured using a Hitachi 7600-110 chemistry autoanalyzer (Hitachi, Tokyo, Japan). Hypertension was defined by systolic blood pressure $\geq 140 \mathrm{~mm}$ $\mathrm{Hg}$, diastolic blood pressure $\geq 90 \mathrm{~mm} \mathrm{Hg}$, or current use of hypertension medication. Type 2 diabetes was defined by a fasting plasma glucose level $\geq 126 \mathrm{mg} / \mathrm{dL}$ or the current use of diabetes medication. Dyslipidemia was defined as triglyceride $\geq 150 \mathrm{mg} / \mathrm{dL}$, low HDL cholester$\mathrm{ol}<50 \mathrm{mg} / \mathrm{dL}$, or current use of dyslipidemia medications. This study was conducted in accordance with the ethical principles of the Declaration of Helsinki and was approved by the institutional review board (IRB) of Yong-in Severance Hospital, Gyeonggi-do, Republic of Korea (IRB approval no., 9-2019-0012). The requirement for informed consent from individual patients was omitted because of the retrospective design of this study.

\section{Hair Mineral Analysis}

Participants were asked not to chemically process (e.g., by dying, perming, straightening, or frosting) their hair for at least 2 weeks before sample collection. Immediately before sample collection, we ensured that the sample was free of all gels, oils, and hair creams using a selfadministered questionnaire. Hair samples (approximately $80 \mathrm{mg}$ ) were obtained from the proximal portion within $5 \mathrm{~cm}$ of the posterior vertex region of the scalp by cutting with stainless steel scissors and were stored in clean plastic bags. We measured the copper and zinc levels in each hair sample, using a microwave temperature-controlled digestion technique and a mass spectrometer (Sciex Elan 6100; PerkinElmer Corp., Waltham, MA, USA). The analytic process was regularly inspected and controlled by the Clinical Laboratory Division of the Department of Health and Human Services (Trace Elements Inc., Addison, TX, USA). The concentrations of copper and zinc are expressed as $\mathrm{mg} / 100 \mathrm{~g}$ of hair with dry weight ( $\mathrm{mg} \%$ ).

\section{Abdominal Fat Computed Tomography}

Abdominal fat CT is an accurate and convenient imaging test available to assess the visceral fat of an individual. We measured intra-abdomi- 
nal (visceral adipose tissue, VAT) by fat measurement CT (Tomoscan 350; Philips, Amsterdam, the Netherlands). The VAT area was assessed at the L4 to L5 level with 3-mm slice thicknesses in the supine position, quantified by defining the intra-abdominal cavity at the internal side of the abdominal and oblique muscle walls surrounding the cavity and the posterior aspect of the vertebral body.

\section{Statistical Analysis}

Demographic and biochemical characteristics of the study population were calculated and expressed as means ( \pm standard deviation) or percentages. Using Pearson's correlation, we measured the strength of correlation between copper, zinc, and the copper-zinc ratio and metabolic indicators, including NLR. A multiple linear regression analysis was used to assess the independent contributions of copper, zinc, and the copper-zinc ratio to NLR after adjusting for confounding variables, including hypertension, type 2 diabetes, and dyslipidemia. All analyses were conducted using the SAS ver. 9.4 statistical software program (SAS Institute Inc, Cary, NC, USA). All statistical tests were two-sided, and statistical significance was determined at a P-value of less than 0.05 .

\section{RESULTS}

Table 1 presents the general characteristics of the study population of 56 subjects ( 11 men and 45 women). The mean age, BMI, and VAT were $46.0 \pm 10.5$ years, $29.0 \pm 4.1 \mathrm{~kg} / \mathrm{cm}^{2}$, and $142.9 \pm 68.8 \mathrm{~cm}^{2}$, respectively. The mean WBC count and NLR were $6.6 \pm 1.5 \times 10^{3}$ cells $/ \mu \mathrm{L}$ and $1.7 \pm 0.8$, respectively. For hair mineral analysis, the mean copper level was $4.8 \pm 7.2 \mathrm{mg} \%$, the mean zinc level was $18.4 \pm 10.1 \mathrm{mg} \%$ and the copper-zinc ratio was $0.3 \pm 0.6$. Overall, hypertension medication was prevalent in $19.6 \%$ of the study population, while the proportions of diabetes medication and dyslipidemia medication use were $14.3 \%$ and $21.4 \%$, respectively.

Table 2 shows the correlation analysis between copper, zinc, copper-zinc ratio, and metabolic indicators. We found that NLR was positively correlated with the copper level $(\mathrm{r}=0.475, \mathrm{P}<0.001)$ and the copper-zinc ratio $(\mathrm{r}=0.494, \mathrm{P}<0.001)$. However, such trends were not sig- nificant in the correlation of NLR with zinc level ( $\mathrm{r}=-0.011, \mathrm{P}=0.936)$. In addition, the level of copper was marginally significant when paired with the level of triglycerides $(\mathrm{P}=0.058)$, while the level of zinc was inversely correlated with the HDL cholesterol level $(\mathrm{P}=0.016)$.

Table 3 shows the independent contributions to NLR of copper, zinc, and the copper-zinc ratio in hair. In multiple regression model 2, after adjusting for age, sex, and BMI, the $\beta$ for NLR was $0.057 \pm 0.014$ $(\mathrm{P}<0.001), 0.002 \pm 0.012(\mathrm{P}=0.897)$, and $0.757 \pm 0.176(\mathrm{P}<0.001)$, in the case of copper, zinc, and the copper-zinc ratio, respectively. We also assessed the association between hair minerals and NLR after additional adjustment for VAT, hypertension, type 2 diabetes, and dyslipidemia. The associations were similar in model 3: $\beta=0.055 \pm 0.015$, $\mathrm{P}<0.001$ for copper; $\beta=-0.004 \pm 0.012, \mathrm{P}=0.765$ for zinc; and $\beta=0.761 \pm$

Table 1. Clinical characteristics of the study population

\begin{tabular}{lc}
\hline \multicolumn{1}{c}{ Characteristic } & Value \\
\hline Age $(\mathrm{y})$ & $46.0 \pm 10.5$ \\
Male gender & $11(19.6)$ \\
Body mass index $\left(\mathrm{kg} / \mathrm{m}^{2}\right)$ & $29.0 \pm 4.1$ \\
Visceral adipose tissue $\left(\mathrm{cm}^{2}\right)$ & $142.9 \pm 68.8$ \\
Fasting plasma glucose $(\mathrm{mg} / \mathrm{dL})$ & $106.5 \pm 24.7$ \\
Total cholesterol $(\mathrm{mg} / \mathrm{dL})$ & $192.9 \pm 37.0$ \\
Triglyceride $(\mathrm{mg} / \mathrm{dL})$ & $154.1 \pm 66.2$ \\
HDL-cholesterol $(\mathrm{mg} / \mathrm{dL})$ & $50.6 \pm 12.2$ \\
White blood cell count $\left(\times 10^{3}\right.$ cells/ $\left.\mu \mathrm{L}\right)$ & $6.6 \pm 1.5$ \\
Neutrophil-lymphocyte ratio & $1.7 \pm 0.8$ \\
Hair mineral (mg\% or ratio) & \\
Copper & $4.8 \pm 7.2$ \\
Zinc & $18.4 \pm 10.1$ \\
Copper-Zinc & $0.3 \pm 0.6$ \\
Hypertension* & $11(19.6)$ \\
Type 2 diabetes & \\
Dyslipidemia &
\end{tabular}

Values are presented as mean \pm standard deviation or number (\%).

HDL, high-density lipoprotein.

*Hypertension was defined as a systolic blood pressure $\geq 140 \mathrm{~mm} \mathrm{Hg}$, diastolic blood pressure $\geq 90 \mathrm{~mm} \mathrm{Hg}$, or the current use of hypertension medication. Type 2 diabetes was defined as a fasting plasma glucose $\geq 126 \mathrm{mg} / \mathrm{dL}$ or the current use of diabetes medication. 抽slipidemia was defined as triglyceride $\geq 150 \mathrm{mg} / \mathrm{dL}$ low HDLcholesterol $<50 \mathrm{mg} / \mathrm{dL}$ or the current use of dyslipidemia medications.

Table 2. Correlation between copper, zinc, and copper-zinc ratio and metabolic biomarkers

\begin{tabular}{|c|c|c|c|c|c|c|}
\hline \multirow{2}{*}{ Variable } & \multicolumn{2}{|c|}{ Copper } & \multicolumn{2}{|c|}{ Zinc } & \multicolumn{2}{|c|}{ Copper-zinc } \\
\hline & r & P-value* & r & P-value* & r & P-valuex \\
\hline Age & 0.054 & 0.694 & 0.079 & 0.694 & 0.124 & 0.370 \\
\hline Body mass index & -0.043 & 0.759 & -0.050 & 0.710 & 0.030 & 0.832 \\
\hline Visceral adipose tissue & -0.002 & 0.987 & 0.051 & 0.712 & 0.058 & 0.676 \\
\hline White blood cell & -0.179 & 0.195 & 0.105 & 0.449 & -0.146 & 0.290 \\
\hline Total cholesterol & 0.003 & 0.980 & 0.360 & 0.008 & -0.153 & 0.278 \\
\hline Triglycerides & 0.261 & 0.058 & -0.045 & 0.753 & -0.044 & 0.757 \\
\hline High-density lipoprotein cholesterol & 0.193 & 0.170 & 0.331 & 0.016 & -0.043 & 0.759 \\
\hline Glucose & -0.013 & 0.927 & -0.129 & 0.356 & 0.085 & 0.546 \\
\hline Neutrophil-lymphocyte ratio & 0.475 & $<0.001$ & -0.011 & 0.936 & 0.494 & $<0.001$ \\
\hline
\end{tabular}

${ }^{*}$ P-value determined by Pearson's correlation analysis. 
Table 3. Multiple regression analysis showing the independent contribution of copper, zinc, and copper-zinc ratio level to the neutrophil-lymphocyte ratio

\begin{tabular}{|c|c|c|c|c|c|c|}
\hline & \multicolumn{2}{|c|}{ Copper } & \multicolumn{2}{|c|}{ Zinc } & \multicolumn{2}{|c|}{ Copper-zinc } \\
\hline & $\beta \pm S E$ & P-value & $\beta \pm S E$ & P-value & $\beta \pm S E$ & P-value \\
\hline Model 1 & $0.053 \pm 0.014$ & $<0.001$ & $-0.001 \pm 0.011$ & 0.936 & $0.710 \pm 0.118$ & $<0.001$ \\
\hline Model 2 & $0.057 \pm 0.014$ & $<0.001$ & $0.002 \pm 0.012$ & 0.897 & $0.757 \pm 0.176$ & $<0.001$ \\
\hline Model 3 & $0.055 \pm 0.015$ & $<0.001$ & $-0.004 \pm 0.012$ & 0.765 & $0.761 \pm 0.185$ & $<0.001$ \\
\hline
\end{tabular}

Model 1: unadjusted; model 2: adjusted for age, sex, and body mass index; and model 3: adjusted for age, sex, body mass index, visceral adipose tissue, hypertension, type 2 diabetes, and dyslipidemia.

SE, standard error.

0.185, $\mathrm{P}<0.001$ for the copper-zinc ratio.

\section{DISCUSSION}

In this cross-sectional study on overweight or obese patients, we observed a positive association between NLR and both the level of copper and the copper-zinc ratio in hair. Furthermore, these were found to be independent factors after additional adjustment for VAT, hypertension, type 2 diabetes, and dyslipidemia.

In previous studies, obesity has been linked to systemic inflammation and has been associated with various inflammatory markers, while NLR is an important predictor for evaluating chronic inflammation. ${ }^{15-19)}$ In particular, NLR may be a significant indicator when the pathophysiology involves inflammation of blood vessels, such as cardiovascular disease. ${ }^{8)}$ In the relationship between NLR and obesity, studies have shown that other markers, such as C-reactive protein (CRP), are more closely related with obesity, while NLR tends to be elevated in obese patients. ${ }^{20-23)}$

Copper is an essential nutrient but may induce oxidative damage. Excessive levels of copper can cause increased oxidative damage to lipids, proteins, and DNA. However, individuals with copper deficiency are less able to withstand oxidative stress. Thus, it is important to maintain the proper concentration of copper in the body. ${ }^{24-26)}$

Zinc functions to maintain a normal immune response, and chronic zinc deficiency increases the inflammatory response. ${ }^{27)}$ In many other chronic inflammatory conditions, zinc levels are low. Low levels of zinc were also found in obesity, one of the known chronic inflammatory conditions. ${ }^{28)}$ Oxidative stress and inflammatory response have shown improvement after zinc replacement. ${ }^{10,29,30)}$ In our study, however, participants presented with normal zinc levels in the hair mineral analysis, and we found no significant correlation between the level of zinc and NLR.

Zinc reduces copper toxicity by promoting the synthesis of metallothionein, which absorbs copper in the liver, intestine, and kidneys and removes copper from its binding site (which promotes radical formation). ${ }^{24)}$ The copper-zinc ratio has been positively related to systemic oxidative stress status: copper has a pro-oxidant property, while zinc has an antioxidant property. Thus, the imbalance of copper and zinc may cause oxidative stress. ${ }^{12)}$ An increased NLR ratio as an oxidative stress burden has been reported to be independent of common inflammatory markers such as CRP. ${ }^{31)}$ A decrease in lymphocyte count is correlated with an increase in hypothalamic-pituitary-adrenal axis hyperactivity, and increases in neutrophil count may lead to enhanced oxidative stress through enzymatic changes such as myeloperoxidase activation. ${ }^{32)}$ In the present study we found that the copper-zinc ratio was significantly associated with NLR but not correlated with metabolic alterations, except for a weak relationship with respect to some parameters. In this regard, the increased copper-zinc ratio may represent increased oxidative burn within the context of a normal WBC count.

Our study has a few limitations that should be mentioned. First, as a cross-sectional study, the exact cause-and-effect relationship between the hair copper-zinc ratio and NLR remains unclear. Prospective longitudinal studies are needed to verify the role of high copper-zinc ratio in hair in the development of obesity-related, chronic inflammation. Second, since all study subjects were volunteers who had visited a single clinic for weight reduction, the way in which the study population was enrolled may have introduced selection bias and prevented us from obtaining an accurately representative sample of the general Korean population. Third, we did not take into consideration the effect of dietary pattern and the use of supplements as well as the hormonal conditions in women that could influence hair mineral levels and NLR ratio. Furthermore, although we excluded subjects with abnormal WBC counts, other inflammatory conditions cannot be completely excluded, and other inflammatory markers (such as CRP) were not measured at the beginning of this study. Despite these limitations, we argue that our effort to elucidate the role of copper-zinc interactions in the preclinical inflammatory state is a distinguishing feature of this study.

In conclusion, we found that a higher copper-zinc ratio in hair within the context of a normal WBC count is positive and independently associated with NLR. Accordingly, we propose the validity of deploying a high hair copper-zinc ratio as a putative oxidative burden among overweight or obese Korean participants, providing an initiative for further nutritional health management of individuals predisposed with obesity-related comorbidity. Further larger-scale studies are warranted to validate these associations.

\section{CONFLICT OF INTEREST}

No potential conflict of interest relevant to this article was reported. 


\section{ORCID}

Sun Young Jeong: https://orcid.org/0000-0001-6667-6140

Hyo Young Shim: https://orcid.org/0000-0002-1664-8878

Yong Jae Lee: https://orcid.org/0000-0002-6697-476X

Byoungjin Park: https://orcid.org/0000-0003-1733-5301

\section{REFERENCES}

1. Marseglia L, Manti S, D’Angelo G, Nicotera A, Parisi E, Di Rosa G, et al. Oxidative stress in obesity: a critical component in human diseases. Int J Mol Sci 2014;16:378-400.

2. Nishimura S, Manabe I, Nagai R. Adipose tissue inflammation in obesity and metabolic syndrome. Discov Med 2009;8:55-60.

3. Johnson AR, Milner JJ, Makowski L. The inflammation highway: metabolism accelerates inflammatory traffic in obesity. Immunol Rev 2012;249:218-38.

4. Jee SH, Park JY, Kim HS, Lee TY, Samet JM. White blood cell count and risk for all-cause, cardiovascular, and cancer mortality in a cohort of Koreans. Am J Epidemiol 2005;162:1062-9.

5. Ohshima H, Tazawa H, Sylla BS, Sawa T. Prevention of human cancer by modulation of chronic inflammatory processes. Mutat Res 2005; 591:110-22.

6. Gillum RF, Mussolino ME, Madans JH. Counts of neutrophils, lymphocytes, and monocytes, cause-specific mortality and coronary heart disease: the NHANES-I epidemiologic follow-up study. Ann Epidemiol 2005;15:266-71.

7. Tsai JC, Sheu SH, Chiu HC, Chung FM, Chang DM, Chen MP, et al. Association of peripheral total and differential leukocyte counts with metabolic syndrome and risk of ischemic cardiovascular diseases in patients with type 2 diabetes mellitus. Diabetes Metab Res Rev 2007; 23:111-8.

8. Balta S, Celik T, Mikhailidis DP, Ozturk C, Demirkol S, Aparci M, et al. The relation between atherosclerosis and the neutrophil-lymphocyte ratio. Clin Appl Thromb Hemost 2016;22:405-11.

9. Guo CH, Wang CL. Effects of zinc supplementation on plasma copper/zinc ratios, oxidative stress, and immunological status in hemodialysis patients. Int J Med Sci 2013;10:79-89.

10. Prasad AS. Zinc: role in immunity, oxidative stress and chronic inflammation. Curr Opin Clin Nutr Metab Care 2009;12:646-52.

11. Guo CH, Chen PC, Yeh MS, Hsiung DY, Wang CL. Cu/Zn ratios are associated with nutritional status, oxidative stress, inflammation, and immune abnormalities in patients on peritoneal dialysis. Clin Biochem 2011;44:275-80.

12. Mezzetti A, Pierdomenico SD, Costantini F, Romano F, De Cesare D, Cuccurullo F, et al. Copper/zinc ratio and systemic oxidant load: effect of aging and aging-related degenerative diseases. Free Radic Biol Med 1998;25:676-81.

13. Mohammed IS, Mohammed AK, Farid YY. Serum copper and zinc levels and copper/zinc ratio in patients with rheumatoid arthritis. Iraqi J Med Sci 2005;4:49-56.

14. Emokpae MA, Fatimehin EB. Copper-to-zinc ratio correlates with an inflammatory marker in patients with sickle cell disease. Sci 2019;1:34.
15. Wołowiec P, Michalak I, Chojnacka K, Mikulewicz M. Hair analysis in health assessment. Clin Chim Acta 2013;419:139-71.

16. Park BJ, Shim JY, Lee HR, Lee JH, Jung DH, Kim HB, et al. Relationship of neutrophil-lymphocyte ratio with arterial stiffness and coronary calcium score. Clin Chim Acta 2011;412:925-9.

17. Fontana L, Eagon JC, Trujillo ME, Scherer PE, Klein S. Visceral fat adipokine secretion is associated with systemic inflammation in obese humans. Diabetes 2007;56:1010-3.

18. El Kassas GM, Shehata MA, El Wakeel MA, Amer AF, Elzaree FA, Darwish MK, et al. Role of procalcitonin as an inflammatory marker in a sample of Egyptian children with simple obesity. Open Access Maced J Med Sci 2018;6:1349-53.

19. Imtiaz F, Shafique K, Mirza SS, Ayoob Z, Vart P, Rao S. Neutrophil lymphocyte ratio as a measure of systemic inflammation in prevalent chronic diseases in Asian population. Int Arch Med 2012;5:2.

20. Bahadir A, Baltaci D, Turker Y, Turker Y, Iliev D, Ozturk S, et al. Is the neutrophil-to-lymphocyte ratio indicative of inflammatory state in patients with obesity and metabolic syndrome? Anatol J Cardiol 2015;15: 816-22.

21. Demir AD, Durmaz ZH, Ozkan T, Demir O, Guckan R, Kilinc C. The ratio of neutrophil lymphocytes and CRP comparison in young obese individuals. Biomed Res 2017;28:7486-90.

22. Furuncuoglu Y, Tulgar S, Dogan AN, Cakar S, Tulgar YK, Cakiroglu B. How obesity affects the neutrophil/lymphocyte and platelet/lymphocyte ratio, systemic immune-inflammatory index and platelet indices: a retrospective study. Eur Rev Med Pharmacol Sci 2016;20:1300-6.

23. Aydin M, Yilmaz A, Donma MM, Tulubas F, Demirkol M, Erdogan M, et al. Neutrophil/lymphocyte ratio in obese adolescents. North Clin Istanb 2015;2:87-91.

24. Gaetke LM, Chow CK. Copper toxicity, oxidative stress, and antioxidant nutrients. Toxicology 2003;189:147-63.

25. Uriu-Adams JY, Keen CL. Copper, oxidative stress, and human health. Mol Aspects Med 2005;26:268-98.

26. Bremner I. Manifestations of copper excess. Am J Clin Nutr 1998;67(5 Suppl):1069S-1073S.

27. Bonaventura P, Benedetti G, Albarede F, Miossec P. Zinc and its role in immunity and inflammation. Autoimmun Rev 2015;14:277-85.

28. Ozata M, Mergen M, Oktenli C, Aydin A, Sanisoglu SY, Bolu E, et al. Increased oxidative stress and hypozincemia in male obesity. Clin Biochem 2002;35:627-31.

29. Kim J, Ahn J. Effect of zinc supplementation on inflammatory markers and adipokines in young obese women. Biol Trace Elem Res 2014;157: 101-6.

30. Cruz KJ, Morais JB, de Oliveira AR, Severo JS, Marreiro DD. The effect of zinc supplementation on insulin resistance in obese subjects: a systematic review. Biol Trace Elem Res 2017;176:239-43.

31. Arbel Y, Shacham Y, Ziv-Baran T, Laufer Perl M, Finkelstein A, Halkin A, et al. Higher neutrophil/lymphocyte ratio is related to lower ejection fraction and higher long-term all-cause mortality in ST-elevation myocardial infarction patients. Can J Cardiol 2014;30:1177-82.

32. Kotani K. Neutrophil/lymphocyte ratio and the oxidative stress burden. Can J Cardiol 2015;31:365. 